\title{
ФИЛОСОФИЯ
}

(специиальность: 09.00.11)

\section{УДК 101}

\section{E.E. Фёдорова}

Донской государственный

технический университет

2. Ростов-на-Дону, Россия

redaction-el@mail.ru

\section{ПРОБЛЕМА СУБЪЕКТА МЕЖЛИЧНОСТНЫХ КОММУНИКАЦИЙ В УСЛОВИЯХ ИНФОРМАЦИОННОГО ОБЩЕСТВА}

\author{
[Elena E. Fedorova The problem of the subject \\ of interpersonal communications \\ in the conditions of the information society]
}

The conceptualization of the problem of the transformation of the subject of interpersonal communications and social values in the information society is presented. A person formed by mod-ern technogenic society is radically depersonalized, which is a deep challenge for a culture in which new forms of interpersonal communications and value orientations must be developed. The main result of the work is the identification of the communicative criterion in the characterization of the information society and the establishment of the fact of the transformation of the social essence of a person as a subject of interpersonal communication into a user of cyberphysical communications.

Key words: interpersonal communication, subject, information society, technosociety.

Глубокие изменения, происходящие в современном мировом сообществе, обусловлены различными причинами политического, экономического, социального и духовного характера. Среди детерминант происходящих изменений следует отметить стремительные темпы развития информационного общества, влияющие на процессы глобализации. Это приводит к изменению процесса приобретения личностной идентичности. Прежде всего это связано с информацией, имеющей большое значение для человека, которая становится все более индивидуализированной, персонифицированной, а также отражающей особенности личностного восприятия мира. Рассматривая основные 
проблемы современного глобального общества, следует отметить проблему проникновения технологий в межличностное пространство. Личностные отношения создают качественно новые формы социальной коммуникации и затрагивают глубокие духовные, психологические, личностные, этические, политические, экономические, научные и другие сферы человеческого бытия.

Цель данной статьи - проанализировать проблему человека как субъекта межличностной коммуникации в сопряжении с процессами развития информационного общества.

Для реализации поставленной цели необходимо решение следующих задач:

1. Выявление сущности информационного общества.

2. Концептуализация понятия «субъект» межличностных коммуникаций в информационном обществе.

Термин «информационное общество» используется с 1970-х гг., но приобрел популярность и в настоящее время широко используется в социальной философии. Устойчивый и ускоренный рост средств массовой информации, образовательного обеспечения и участия, а также компьютерных коммуникационных технологий привел многих к утверждению, что сопутствующий информационный взрыв отличает новую эпоху. Информационное общество - это общество, в котором информация является определяющей чертой, в отличие от индустриального общества, где движущими элементами были паровая энергия и ископаемое топливо.

Хотя этот термин используется часто, он недостаточно концептуализирован. Существует шесть аналитически обособленных критериев определения, используемых комментаторами информационного общества:

1. Технологический. Наиболее распространенное определение состоит в том, чтобы выделить рост информационно-коммуникационных технологий (ИКТ) как сигнал возникновения информационного общества. Часто подразумевается, что ИКТ одновременно определяют и создают информационное общество. Технологические меры кажутся надежными, но при рассмотрении они расплывчаты (например, они варьируются от ксероксов до персональных компьютеров, Интернета, видеоигр, до оцифровки в целом).

2. Экономический. Это говорит о том, что информационное общество это такое общество, в котором вклад информационных предприятий и 
профессий (например, издательского дела, индустрии развлечений, консалтинга) со временем увеличился и теперь превышает вклад промышленности и сельского хозяйства в валовом национальном продукте. Обычно такие аналитики используют термин «информационная / цифровая экономика» для описания ситуации, в которой информационные отрасли занимают основную долю ВВП.

3. Профессиональный. Этот подход наиболее тесно связан с теорией постиндустриализма Дэниела Белла. В книге Белла «The Coming of PostIndustrial Society» (1973) информационное общество описывается как общество, в котором большинство рабочих мест являются информационными. Таким образом, такие профессии, как исследователи, юристы, консультанты и учителя, являются информационно интенсивными, включающими в себя производство информации, анализ и коммуникацию, и результатом является измененное состояние, а не объект. Это в отличие от рабочих мест индустриального общества, таких как эксплуатация машин и добыча полезных ископаемых, где продукт является физическим благом, а труд в основном ручной.

4. Пространственный. Здесь акцент делается на сети, по которым течет информация. Информационные сети оказывают глубокое влияние на организацию времени и пространства, а также на другие отношения, позволяя осуществлять коммуникацию в реальном масштабе времени в планетарном масштабе. Трилогия Мануэля Кастельса «Информационная эпоха: Экономика, общество и культура» (1996-1998) является главным утверждением этой позиции. Это синоним того, что он называет сетевым обществом. Метафору подвижности вдоль границ (например, дороги, железные дороги, телекоммуникационные системы, обеспечивающие возможность передвижения) можно считать центральной для информационных обществ.

5. Культурный. Этот подход подчеркивает рост символов и знаков в течение последних десятилетий, поскольку информационное общество это общество, в котором есть всепроникающее телевидение, реклама, множество стилей жизни, множество этнических групп, множество гибридных музыкальных выражений, всемирная паутина и так далее. Она тесно связана с культурологией и интересом к постмодернизму. 
6. Теоретический. Это говорит о том, что информационное общество - это такое общество, в котором теоретическая информация/знание (то что является абстрактным, обобщаемым и кодифицированным в текстах) имеет приоритет над практическим и является конститутивным практически для всего, что делается. Это контрастирует с предыдущими обществами, в которых преобладали практические требования, ноу-хау и обычаи.

Мы выделим еще один критерий информационного общества - коммуникативный. Новые технологии меняют принципы межличностных коммуникаций и трансформируют саму человеческую сущность. Вплоть до середины $\mathrm{XX}$ века процесс развития философии техники отражал эпоху массового производства и потребления. Проблема отчуждения вновь начала вызывать интерес после бума 1960-х гг. и всплеска внимания в 1990-х гг. С 1960-х гг. вместо оптимизма появилась тревога по поводу научно-технической революции в связи с отчуждением техники, с «вытеснением» человека как субъекта, творца и потребителя культуры из технологизированной социальной реальности. Индивидуализированное производство и потребление характерно для постиндустриального общества $[1 ; 5]$.

Говоря о субъекте, мы понимаем под этим понятием не просто метафи зический, но и определенный антропологический концепт. Как пишет Е.Л. Черткова, после Декарта «слово и понятие «субъект»... становится именем собственным и сущностным для человека» [6, с. 118]. Если «в метафизике до Декарта под субъектом понималось как раз сущее, бытие» (вспомним, что латинское «subjectum» значит «подлежащее», это субстрат, носитель качеств, предикатов), то «через Декарта... «субъектом» становится в метафизике преимущественно человек, человеческое Я» [6, с. 117]. К анализу, проведенному Е.Л. Чертковой, добавим, что идея человека как субъекта имеет долгую историю становления в западной, европейской культуре (как берущей начало в древнегреческой культуре). Она начинается с эмансипации человека от древнегреческого фатума, негативируется в библейской истории о своенравном человеческом действии как причине грехопадения, одновременно обретая положительный потенциал благодаря теме человеческого выбора между возвращением к богу и присоединением ко всему богопротивному. В эпоху Возрождения совершается возврат к античному «культу человека» в соединении с представлением о человеке как подобии 
Творца, а Просвещение формулирует целью реализацию каждым в своей жизни образа - и программы - свободного субъекта - если и не свободного в действиях, то свободного в мыслях, т.е. самостоятельно мыслящего. Новоевропейская субъектоцентристская метафизика - звено в представленной цепи, а складывающуюся описанным путем концепцию человека можно реконструировать как представление его в качестве центра мира, вершителя его судьбы - творца и преобразователя, в котором и через которого мир только и обретает полноту бытия [5, с. 154-174].

Практическая важность любого антропологического концепта состоит в том, что он диктует определенную логику человеческой активности в мире. От того, как мы мыслим человека, зависит то, как выглядит реальная деятельность - научно-исследовательская, управленческая, общественно-политическая и др. Иными словами, антропологический концепт подразумевает определенную праксиологическую модель. В случае концепта «субъект» эта модель претерпела ряд трансформацией, следуя за трансформациями самого концепта. Тем не менее, мы бы выделили следующие основополагающие принципы, формирующие понятие субъекта и связанные с ним понятийные и концептуальные образования: саморефлексивности, рациональности (в критико-рефлексивном ее понимании), автономии, самоценности, свободы и ответственности. Все эти принципы можно толковать по-разному, например, склоняясь либо к гуманизму, либо к агрессивной активистской позиции (гуманизм не обязательно требует жесткого активизма). То же можно сказать по поводу субстанциалистского или антисубстанциалистского понимания человека: саморефлексивность допускает прочтения в качестве как самопрозрачности, так и самопроектности, и если субъект Декарта саморефлексивен в первом смысле и субстанциален, то в экзистенциализме Ж.-П. Сартра или Х. Ортеги-и-Гассета субъект выступает как проект самого себя и никакой изначальной сущностью не обладает. Но при этих и многих других нюансах трактовок неизменным остается аксиологическое наполнение понятии «субъект», на котором и делает акцент Е.Л. Черткова в упомянутой выше статье. Как четко выражает это наполнение Н. Луман, «используя понятие субъект, мы голосуем за автономию и против гетерономии, за эмансипацию и против манипуляции» [4, с. 176]. 
В высказывании Лумана сквозит ирония, потому что, говоря оптимистично, эмпирия не дает нам примеров ни чистой автономии, ни чистой эмансипации. Если же мы будем более пессимистичными (или, в другой терминологии, более «реалистичными»), то должны признать, что эмпирическое исследование дает нам преимущественно образцы гетерономии и манипуляции. Для самого Лумана «оптимистичный» и «пессимистичный» образ социальной реальности зависит от операций различения, от типа самоописания, которым характеризуется общество в данный момент. С Луманом можно согласиться в том смысле, что решение вопроса действительно зависит от того, что мы соглашаемся считать свободой воли, каковы принимаемые нами критерии признания действия автономным и т.д. Однако операция различения не абсолютно произвольна - в том смысле, что, хотя мы можем с успехом обосновывать различные варианты, у каждого самоописания свои последствия, одни из которых явно - на практике - оказываются неприемлемыми.

Аргументируя выбор деятельностного подхода к анализу межличностных коммуникаций в информационном обществе, мы можем противопоставить концепты деятельности и практики, исходя главным образом из нагруженности понятия «практика» мотивами противопоставления материально-практического и деятельностно-созерцательного, инструментализма и технократизма, с одной стороны, и нейтральности на этом фоне, общности понятия «деятельность» - с другой. Но понятие практики несет еще одну смысловую нагрузку - имеющую те самые ощутимые на практике последствия - когда в отличие от деятельности практика понимается как нечто, не требующее присутствия субъекта в качестве своего истока и руководящего центра. Практика в таком понимании процессуальна - это поток, в котором субъект является носителем, но не движителем. Она, разумеется, невозможна без человека, но вместе с тем в определенном смысле подчиняет того, благодаря кому реализуется: «Реально овладеть этой (практической) логикой может лишь тот, кем она полностью овладела; тот, кто ею обладает, но в такой же степени, в какой она сама владеет им» $[1$, с. 33]. Подобный подход позволяет перейти от описания субъектов и их деятельности к описанию механизма самих практик. Данная теоретическая стратегия реализуется, в том числе, в социальной теории Н. Лумана, предполагающей, что различные подсистемы общественного целого «образуются в процессе протекания общественных операций» $[3$, с. 
10], каковыми оказываются коммуникации. Отсюда следует различение социального и несоциального, и во вторую группу попадают «люди, сознания, организмы, артефакты» [3], и поэтому «никакой конкретный человек не является необходимым для общества» [3, с. 11]. Как резюмирует Луман, «...peшающее значение здесь имеет то, что коммуникация продолжается - какое бы содействие здесь не оказывало необходимое для процесса коммуникаций сознание. В коммуникации не может быть зафиксировано... присутствуют ли при этом системы сознания «аутентично» или лишь оказывают необходимое содействие для продолжения коммуникаций» [4, с. 14].

Нельзя сказать, что описанный теоретический ход плох. Со многими пунктами критики Луманом концепта «субъект» можно согласиться. Действительно, отсылки к консенсусу, интерсубъективности, мотивам, нормативному разуму и пр. при рассмотрении функционирования социальных систем оказываются не очень адекватными инструментами описания и объяснения, а значит, и предсказания. Поэтому в контексте управленческих задач социальная онтология Лумана представляется весьма заманчивой. С ценностных и этико-праксиологических позиций новоевропейский активизм также выглядит более чем скомпрометированным: именно на него возлагают вину за экологический кризис, умножение иных рисков научно-технического развития, мировоззренческую потерянность и пр., а значит, и в этом контексте системный подход оказывается привлекательной альтернативой. Немаловажно, что системная парадигма не единственный возможный вариант реализации ухода от субъектоцентризма. Еще один вариант предлагает акторно-сетевая теория (АСТ) общества, в которой люди «считаются», но уже не в качестве единственных производителей социального. Акторами в АСТ могут быть и материальные объекты, другими словами здесь «люди, сознания, организмы, артефакты» возвращаются в социальную теорию и социальную онтологию, и принципиально важно, что возвращаются они на паритетных началах.

Сделаем шаг назад и посмотрим, как обрисованный концептуальный расклад видится с точки зрения, скажем так, сторонников более классических концептуальных форм. Так, Е.Л. Черткова констатирует кризис «трансцендентальной концепции» субъекта и «возвратное движение» к его «эмпирическому понимаю», которое оборачивается радикальной релятивизацией и «де- 
субъективацией субъекта». Она рассматривает этот процесс как опасность не менее грозную, чем тот же экологический кризис. Почему же? Потому что в такой онтологии нет инстанции, которая несла бы ответственность за происходящее. Действительно, «коммуникация продолжается», что бы ни происходило с отдельными людьми и целыми сообществами. Предъявлять этические претензии к процессуальному нелепо. Если человек мыслиться лишь как переносчик информации и носитель какого-то процесса, то о какой ответственности может идти речь? Именно в силу сказанного автономный (самодетерминация, самоопределение) и способный к рациональным оценке и выбору субъект - тот идеал и та этико-праксиологическая модель, которая должна быть сохранена и реализовываться.

Техногенная цивилизация формируется в специфических культурных условиях, связанных с вышеописанным кризисом концепта «субъект», и здесь надо добавить, что дело не только во внутритеоретических проблемах, сами особенности бытия современного человека противятся представлению его с помощью субъектной оптики, и упомянутые социальные теории - как раз попытка работать с этими особенностями. К ним относятся: столкновение культур при осознании их самоценности, невозможности выбрать лучшую, более прогрессивную и каким-либо образом их ранжировать; размывание традиционных ценностных рамок; увеличение числа коммуникаций; динамичность повседневного пространства и др. Все это проблематизирует самоидентификацию. Она уже не может протекать латентно и однократно. Наоборот, неоднозначность личностного выбора выдвигает ее на первый план, а увеличение числа ситуаций, требующих такого выбора, удерживает на этом переднем плане. Поэтому самоидентичность, гарантирующая единство, или, можно сказать, субстанциальность субъекта, постоянно ставится под вопрос, порождая представления об уникальных кризисных обстоятельствах или о конструктивном характере самоидентичности (что в целом верно) - в лучшем случае, и ее множественной случайной детерминации (что уже спорно) - в худшем, и, строго говоря, необязательности ее конкретного содержания в обоих случаях. Это означает, что человек не управляет миром и собой, он лишь точка пересечения множественных процессов, порождаемых различными факторами, или нечто, что создается, пишется с той или иной степенью сознательности и целесообразности [2]. 
Последние научные и технологические разработки настолько трансформируют отношение к сущности человека и природы, что можно говорить о новом «постнатуральном» обществе. Достижения в области техники, генетики, нанотехнологий и квантовой механики создают условия для общества, в которых ограничения, налагаемые природой, преодолеваются технологическими вмешательствами на молекулярном уровне жизни и материи. Донна Харауэй (1991) описывает новую реальность «киборга», которая становится возможной, когда возможности тела и разума усиливаются различными протезами, такими как искусственные органы или части тела [7]. Когда эти искусственные протезы не просто заменяют дефектную анатомию, но улучшают ее, можно утверждать, что условия жизни стали «постнатуральными». В своем фантастическом романе «Святой огонь» (1996), Брюс Стерлинг экстраполирует последние достижения в области медицинских знаний, чтобы представить будущую эпоху постчеловеческого существования, то есть период, в течение которого смертность, которая определяла состояние человека на протяжении тысячелетий, была эффективно устранена с помощью технологий сохранения жизни [9].

Благодаря генной инженерии ученые смогли создавать новые формы жизни с начала 1970-х гг. Это исследование подпитывается перспективой использования генетических технологий для решения таких проблем, как болезни и старение, на уровне молекулы ДНК, которая содержит «план» жизни. Пищевые культуры могут быть сконструированы так, чтобы они были устойчивы к вредителям, засухоустойчивы или были более продуктивными. Таким образом, эти технологии теоретически способны решить налагаемые окружающей средой ограничения на нашу коллективную способность кормить голодных. Точно так же нанотехнологии, которые позволяют создавать физические свойства материалов на атомном и субатомном уровне, создают возможность бесконечно манипулируемой вселенной. Футуролог Рэй Курцвейл (Ray Kurzweil, 2009) предполагает, что на основе нанотехнологий «мы сможем создавать практически все, что нам нужно в физическом мире, из информационных файлов с очень недорогими исходными материалами» [8]. Другие предупреждают, что сложность рисков, связанных с внедрением этих молекулярных технологий в окружающую среду делает их использование опасным, а их последствия неисчислимыми. Это очень «постнатуральная» дилемма; та, которой не могло случиться с людьми в более ранних типах общества. 
Таким образом, одна из особенностей техногенного общества, каким оно сегодня является, как отмечают исследователи [5], в его ориентации на преобразование не только среды обитания человека, а самого человека - его телесности и даже биологической природы, что безусловно оказывает влияние на процесс межличностных коммуникаций. «Путем разрушения ценностной матрицы, имеющей и экзистенциальное, и культурно-интегративное значение для социального субъекта, техносоциум заменяет ее нормативно-регулятивной, по образу машинных протоколов, тем самым он невольно устанавливает отрицательную обратную связь с субъектными ценностными матрицами, унифицируя их сообразно нормативам коммуникации и интеракций, соответствующих стандартам протоколов киберфизической реальности», создавая культуру коммуникации «субъектов-пользователей», «субъектов-операторов» [5].

В информационном обществе техногенной цивилизации социальная сущность человека, его личность как интегративный социокультурный феномен субъектно деградирует или упрощается, человек обречен на сведение к чемуто - к машине, в которую он постепенно превращается, к виртуальному миру, в который интегрируется как его часть, к природному в себе, к пространству коммуникаций и попперовского мира.

Технологическое развитие, настолько же, насколько может стать средством достижения целей, может превратить человека в объект, в носителя безличностного процесса, ставя под сомнение его способность определять цели и принимать самостоятельные решения, т.е. подрывая тем самым потенциал субъектности личности. В отношении техносреды субъектом выступает не индивид и даже не отдельное общество, а человечество в целом. Но существует ли оно иначе, нежели как абстракция? Если и да, то весьма виртуально, и ни историческое, ни общественно-политическое конструирование не делает его той инстанцией, которая несет ответственность за происходящее.

Таким образом, информационно-технологический бум не только разнообразил технологии межличностных коммуникаций (позволяя нам присутствовать во многих контекстах одновременно, выводя нас за границы присутствия физического), но внес свои особенности в процесс коммуникации: появление спама, обесцененность информации, погружение в виртуальный мир, трансформация ценностных ориентаций. В этих условиях понятие субъектности связывается с децентрированностью, отстраненностью и утратой аутен- 
тичности [5]. Следовательно, формирование органических, а не механических оснований межличностных коммуникаций в техносоциуме является одной из важнейших задач информационно-технологической революции, базовым элементом ее социогуманитарных измерений. Сегодня субъекту уже нельзя атрибутировать какие-либо фиксированные качества, которые можно описывать или тестировать. Возможно, субъектность как раз и рождается из отчужденности, и именно эта изначальная «негарантированность субъектной позиции» и подталкивает личность к самоопределению.

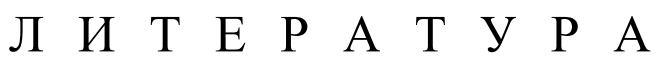

1. Бурдье П. Практический смысл / Пер. с фр.: А.Т. Бикбов, К.Д. Вознесенская, С.Н. Зенкин, Н.А. Шматко. СПб.: Алетейя, 2001.

2. Загидуллин Ж.К., Иванов Д.В., Труфанова Е.О. Сознание: объяснение, конструирование, рефлексия. М.: ИФ РАН, 2016.

3. Луман Н. Общество как социальная система / Пер. с нем. А. Антоновского. М.: Логос, 2004.

4. Луман Н. Самоописания / Пер. с нем. А. Антоновского, Б. Скуратова, К. Тимофеева М.: Логос, ИТДГК Гнозис, 2009.

5. Социо-антропологические измерения конвергентных технологий. Методологические аспекты / Аршинов В.И., Асеева И.А., Буданов В.Г. и др. Курск: Университетская книга, 2015.

6. Черткова Е.Л. Парадоксальная субъективность или субъективность без субъекта // Субъективный мир в контексте вызовов современных когнитивных наук / Общ. Ред. И сост. В.П. Лекторский. М.: Аквилон, 2017.

7. Haraway Donna. (1991). A cyborg manifesto: Science, technology and socialist-feminism in the late $20^{\text {th }}$ century. Simians, cyborgs and women: The reinvention of nature (Ch. 8). London: Free Association.

8. Kurzweil Ray. (2009). Ray Kurzweil on the future of nanotechnology. Big think. Retrieved, Oct. 4, 2015, from http://bigthink.com/videos/raykurzweil-on-the-future-of-nanotechnology

9. Sterling Bruce. (1996). Holy fire. New York: Bantam Spectra. 


\section{$\begin{array}{lllllllllll}\mathrm{R} & \mathrm{E} & \mathrm{F} & \mathrm{E} & \mathrm{R} & \mathrm{E} & \mathrm{N} & \mathrm{C} & \mathrm{E} & \mathrm{S}\end{array}$}

1. Bourdieu P. Practical sense / Trans. from French: A. T. Bikbov, K. D. Voznesenskaya, S. N. Zenkin, N. A. Shmatko. SPb.: Aleteia, 2001.

2. Zagidullin Zh.K., Ivanov D. V., Trufanova E. O. Consciousness: explanation, construction, reflection. Moscow, 2016.

3. Luman N. Society as a social system. A. Antonovsky. Moscow, 2004.

4. Luman N. Self-Description / Trans from German A. Antonovsky, B. Skuratova, K. Timofeeva M.: Publishing house "Logos", Itdgc "Gnosis", 2009.

5. Socio-anthropological dimensions of convergent technologies. In Methodological aspects / Arshinov.I., Aseeva I. A., Budanov V. G., and others. / Collective monograph. Kursk: ZAO "University book", 2015.

6. Chertkova E. L. Paradoxical subjectivity or subjectivity without a subject // Subjective world in the context of challenges of modern cognitive Sciences / General ed. and comp. V. P. Lektorsky (Rel. editor), E. O. Trufanova, A. F. Yakovleva. Moscow: Aquilon, 2017.

7. Haraway Donna. (1991). Cyborg Manifesto: Science, technology, and social feminism in the late 20th century. Simians, cyborgs, and women: the reinvention of nature (Chapter 8). London: Free Association.

8. Kurzweil Ray. (2009). Ray Kurzweil on the future of nanotechnology. Think carefully. Retrieved, Oct. 4, 2015, from http://bigthink.com/videos/raykurzweil-on-the-future-of-nanotechnology

9. Sterling Bruce. (1996). Holy fire. New York: Bantam Spectra.

12 февраля 2020 г. 